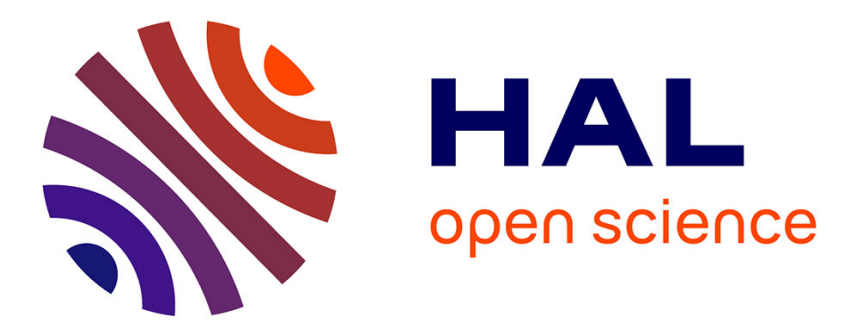

\title{
Liquid-liquid dispersion in a continuous oscillatory baffled reactor - Application to suspension polymerization
}

Emeline Lobry, Thierry Lasuye, Christophe Gourdon, Catherine Xuereb

\section{- To cite this version:}

Emeline Lobry, Thierry Lasuye, Christophe Gourdon, Catherine Xuereb. Liquid-liquid dispersion in a continuous oscillatory baffled reactor - Application to suspension polymerization. Chemical Engineering Journal, 2015, vol. 259, pp. 505-518. 10.1016/j.cej.2014.08.014 • hal-01061567

\section{HAL Id: hal-01061567 https://hal.science/hal-01061567}

Submitted on 8 Sep 2014

HAL is a multi-disciplinary open access archive for the deposit and dissemination of scientific research documents, whether they are published or not. The documents may come from teaching and research institutions in France or abroad, or from public or private research centers.
L'archive ouverte pluridisciplinaire HAL, est destinée au dépôt et à la diffusion de documents scientifiques de niveau recherche, publiés ou non, émanant des établissements d'enseignement et de recherche français ou étrangers, des laboratoires publics ou privés. 


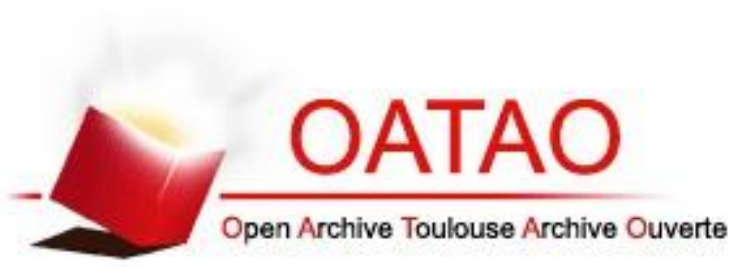

Open Archive Toulouse Archive Ouverte (OATAO)

OATAO is an open access repository that collects the work of Toulouse researchers and makes it freely available over the web where possible.

This is an author-deposited version published in: http://oatao.univ-toulouse.fr/ Eprints ID: 11968

Identification number: DOI:10.1016/j.cej.2014.08.014

Official URL: http://dx.doi.org/10.1016/j.cej.2014.08.014

\section{To cite this version:}

Lobry, Emeline and Lasuye, Thierry and Gourdon, Christophe and Xuereb, Catherine Liquid-liquid dispersion in a continuous oscillatory baffled reactorApplication to suspension polymerization. (2015) Chemical Engineering Journal, vol. 259 . pp. 505-518. ISSN 1385-8947

Any correspondence concerning this service should be sent to the repository administrator: staff-oatao@inp-toulouse.fr 


\title{
Liquid-liquid dispersion in a continuous oscillatory baffled reactor - Application to suspension polymerization
}

\author{
Emeline Lobry ${ }^{\mathrm{a}, \mathrm{b}, *}$, Thierry Lasuye ${ }^{\mathrm{c}}$, Christophe Gourdon ${ }^{\mathrm{a}, \mathrm{b}}$, Catherine Xuereb ${ }^{\mathrm{a}, \mathrm{b}}$ \\ a Université de Toulouse, INPT, UPS, Laboratoire de Génie Chimique, 4, Allée Emile Monso, F-31030 Toulouse, France \\ ${ }^{\mathrm{b}}$ CNRS, Laboratoire de Génie Chimique, F-31030 Toulouse, France \\ ${ }^{\mathrm{c}}$ Ineoschorvinyls, Chemin des Soldats, 62670 Mazingarbe, France
}

\section{H I G H L I G H T S}

- We study the batch to continuous transposition for process based on liquid-liquid dispersion.

- Liquid-liquid dispersion in a continuous oscillatory baffled reactor is thoroughly studied.

- Oscillation is the main parameters responsible for droplet breakage.

- Net flow Reynolds number does not affect the mean droplet size but allows the control of the residence time.

- Vinyl acetate suspension polymerization can be carried out continuously, including the sticky step, in continuous oscillatory baffled reactor.
G R A P H I C A L A B S T R A C T
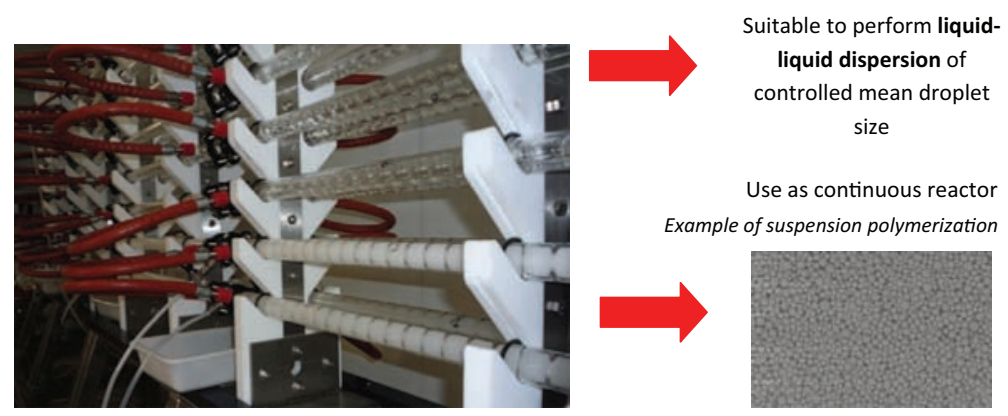

Keywords:

Continuous oscillatory baffled reactor

Liquid-liquid dispersion

Suspension polymerization

\begin{abstract}
A B S T R A C T
Reducing energy costs, improving safety, minimizing waste are the current aims of chemical engineering. Process intensification in fine chemistry has been extensively studied but less work refers to heterogeneous reactions involving two liquid phases. This paper focuses on batch to continuous suspension polymerization transposition and especially on the liquid-liquid dispersion step. The main features of suspension polymerization reaction are based on (i) the initial liquid-liquid dispersion requiring a controlled size and narrow distribution and (ii) on the control of the final particle size during the agglomeration step by avoiding fouling which is a bottleneck for continuous flow. For the continuous transposition, liquid-liquid dispersion and reaction studies are carried out in continuous oscillatory baffled reactor (COBR) which is a multipurpose reactor. Its suitability to overcome the bottlenecks is demonstrated through the investigation of the oscillating and flow conditions or the dispersed phase holdup. A controlled droplet size distribution can be achieved. Oscillation is the main parameter responsible for droplet breakage. The suitable conditions to obtain stable dispersion are determined. For one of the first times, COBR is used for suspension polymerization.
\end{abstract}

* Corresponding author at: Université de Toulouse, INPT, UPS, Laboratoire de Génie Chimique, 4, Allée Emile Monso, F-31030 Toulouse, France.

E-mail address: emeline.lobry@ensiacet.fr (E. Lobry).

\section{Introduction}

Liquid-liquid dispersions involve the droplets generation of controlled droplet size and distribution. They are implied within 


\begin{tabular}{|c|c|c|c|}
\hline \multicolumn{4}{|c|}{ Nomenclature } \\
\hline$A$ & amplitude [m] & & \\
\hline$C_{D}$ & standard orifice coefficient & \multicolumn{2}{|c|}{ Greek symbols } \\
\hline$D_{a x}$ & axial dispersion coefficient $\left[\mathrm{m}^{2} \mathrm{~s}^{-1}\right]$ & & mean energy dissipation rate due to oscillatory flow \\
\hline$D_{o}$ & annular opening diameter [m] & & {$\left[\mathrm{W} \mathrm{kg}^{-1}\right]$} \\
\hline$d_{32}$ & mean Sauter diameter $[\mathrm{m}]$ & & mean energy dissipation rate due to net flow $\left[\mathrm{W} \mathrm{kg}^{-1}\right]$ \\
\hline$D$ & internal column diameter $[\mathrm{m}]$ & & continuous phase density $\left[\mathrm{kg} \mathrm{m}^{-3}\right]$ \\
\hline$D_{h}$ & hydraulic diameter [m] & & dispersed phase density $\left[\mathrm{kg} \mathrm{m}^{-3}\right]$ \\
\hline$f$ & frequency $\left[\mathrm{s}^{-1}\right]$ & & interfacial tension $\left[\mathrm{N} \mathrm{m}^{-1}\right]$ \\
\hline$h$ & baffle spacing $[\mathrm{m}]$ & $v$ & kinematic viscosity $\left[\mathrm{m}^{2} \mathrm{~s}^{-3}\right]$ \\
\hline$L$ & reactor length $[\mathrm{m}]$ & $\Phi$ & holdup \\
\hline$N$ & number of baffles per unit length $\left[\mathrm{m}^{-1}\right]$ & & \\
\hline$N_{t o t}$ & total number of baffles in the column & \multicolumn{2}{|c|}{ Dimensionless numbers } \\
\hline$U, u$ & global velocity $\left[\mathrm{m} \mathrm{s}^{-1}\right]$ & Pe & Peclet number \\
\hline$U_{0}$ & net flow velocity [ $\mathrm{m} \mathrm{s}^{-1}$ ] & & net flow Revnolds number \\
\hline & pulsation velocity $\left[\mathrm{m} \mathrm{s}^{-1}\right]$ & $\begin{array}{l}\kappa e_{n} \\
\operatorname{Re}_{0}\end{array}$ & oscillatory Reynolds number \\
\hline & continuous phase flow rate & $\operatorname{Re}_{0 h}$ & hydrodynamic oscillatory Reynolds number \\
\hline$\Delta P$ & pressure drop [Pa] & $W e_{h}$ & hydrodynamic Weber number \\
\hline$T$ & transparency factor [dimensionless] & & \\
\hline$Q_{d}$ & dispersed phase flow rate $\left[\mathrm{m}^{3} \mathrm{~s}^{-1}\right]$ & & \\
\hline$t$ & time $[\mathrm{s}]$ & & \\
\hline
\end{tabular}

different processes including liquid-liquid extraction [1], crystallization [2-4] or polymerization to control final particle or latex properties $[5,6]$. For such separation techniques or reactions, it is crucial to control accurately the dispersion because it is directly related to efficiency of processes. Among the process intensification route, homogeneous reactions have been deeply investigated as well as nonpolymer reactions [7]. Batch to continuous transposition is often reported to increase the product yield and quality, decrease the use of reactants (catalysts), solvent or other materials, improve safety and allow the work at extreme operating conditions. Few studies focus on batch to continuous transposition of liquid-liquid reactions and especially on two-phase polymerization reactions $[8,9]$. Consequently, in this paper, suspension polymerization is considered. Traditionally performed by thermally initiated radical polymerization in batch stirred tank reactors, the continuous transposition is based on the final product properties and kinetics observation. The initial properties of the liquid-liquid dispersion will strongly impact the properties of the final polymer beads or pearls [10]. Suspension polymerization can then be divided into three different steps [11,12]: (i) a liquid-liquid dispersion step, (ii) the reaction steps in which the polymerizing droplets can agglomerate leading to the final polymer particle size and (iii) a step enabling to reach a conversion between $80 \%$ and $90 \%$ without change in the polymer particle size. Fig. 1 sums up the steps and underlines the limitations of the suspension polymerization reaction.

The first bottleneck in the continuous transposition remains in the droplets production. The initial dispersion requires controlled mean droplet diameter and droplet size distribution. It has to be stable enough to prevent from coalescence and destabilization in course of polymerization. Different continuous processes are available to create liquid-liquid dispersion including membrane [13], rotor-stator [14], static mixer [15-17], colloid mills [14,18], high pressure homogenizer [19], mixer-settler [20] and pulsed column $[21,22]$. A remarkable feature of continuous liquid-liquid dispersion processes are their ability to create quickly droplet of controlled size. Whereas in batch stirred tank reactors, the emulsification time, defined as the time needed to reach stabilized mean droplets sizes, is typically about $15-30 \mathrm{~min}$ [17,23-26], this time can be a limiting step when it comes to continuous process owning residence time ranging from microsecond, to millisecond, to second [15-19].

Table 1 provides some examples of mean droplet size correlation including their range of applications depending on the chemical parameters (viscosity, densities, and interfacial tension), equipment parameters (porosity, pore diameter, pipe diameter, stirrer dimension....) and the operating conditions (flow rate, shear rate, pulsation...). Their limitations are underlined. Balances between hydrodynamic conditions and physico-chemical parameters are different from batch in continuous processes because breakage, coalescence phenomenon and interface stabilization act on different time scales. It is important to understand the mechanisms which display the droplet size in this type of continuous liquid-liquid contactors. These different contactors can thus be used to generate droplets and be associated with different
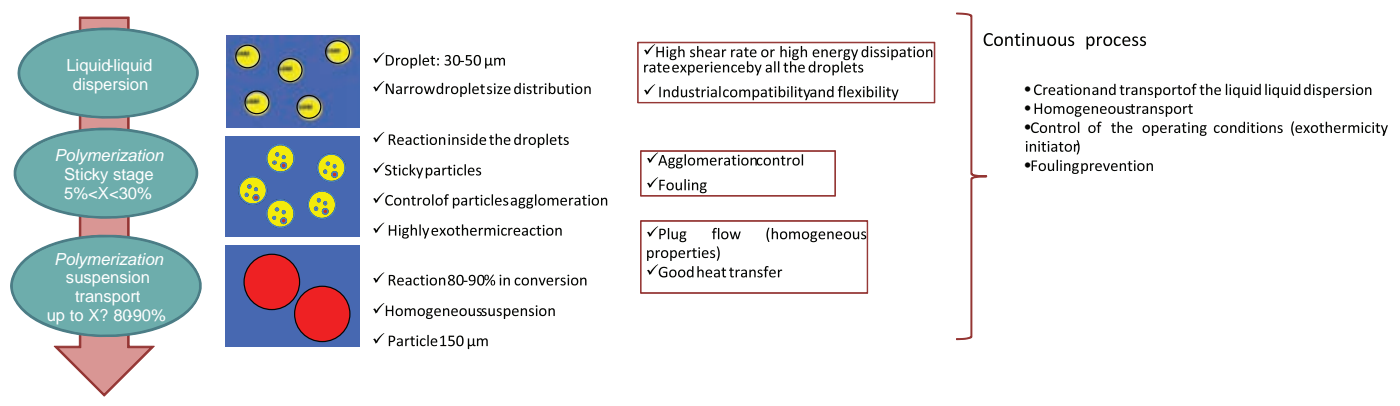

Fig. 1. Steps and limitation for continuous suspension polymerization. 
Table 1

Droplet size correlations for different liquid-liquid contactors, $d_{32}$ is the mean Sauter diameter, $D_{h}$ the hydraulic diameter, $D_{o}$ is the pore diameter, $\mu_{c}$ is the continuous phase viscosity, $\rho_{c}$ and $\rho_{d}$ are the continuous and dispersed phase density, $\rho_{e}$ is the mixture density, $V_{0}$ is the flow velocity, $\varepsilon$ is the porosity, $\sigma$ is the interfacial tension and $\gamma$ the continuous phase shear rate.

\begin{tabular}{|c|c|c|c|c|}
\hline Literature & Contactor type & $\begin{array}{l}\text { Residence } \\
\text { time }\end{array}$ & Limitations & Correlations \\
\hline [15] & Static mixer SMV & $0.04-0.08 \mathrm{~s}$ & $\begin{array}{l}\text { - High flow rate } \\
\text { - Pressure drop }\end{array}$ & $\begin{array}{l}\frac{d_{32}}{D_{h}}=K W e_{h}^{-0.6} R e_{h}^{0.1} \\
W e_{h}=\frac{\rho_{c} V_{0} D_{h}}{\sigma} R e_{h}=\frac{\rho_{e} V_{0} D_{h}}{\varepsilon \mu} \\
\sigma: 3-7 \mathrm{mN} \mathrm{m}^{-1}, \rho_{d} / \rho_{c}: 0.77-0.87, \mu_{d} / \mu_{c}: 0.28-0.94, \Phi: 10-60 \% \\
\text { vol }\end{array}$ \\
\hline [27] & Membrane & & $\begin{array}{l}\text { - Few industrial applications } \\
\text { - Low flow rate }\end{array}$ & $\begin{array}{l}\frac{D}{D_{0}}=\left(a+b W e^{1 / 2}\right) C a^{-1 / 2} \\
W e=\frac{\rho_{D} Q_{D}^{2}}{D_{0}^{3} \sigma} C a=\frac{\mu_{c} \dot{\gamma} D_{0}}{\sigma} \\
\sigma: 8-9.5 \mathrm{mN} \mathrm{m}^{-1}, \rho_{d} / \rho_{c}: 0.82-1.33, \mu_{d} / \mu_{c}: 10.5-13.8\end{array}$ \\
\hline [28] & Batch reactor & $30 \mathrm{~min}$ & - Emulsification time & $\begin{array}{l}\text { Summary of different correlation in the mentioned study } \\
d_{32}=1.72 .10^{-2} R e_{o}^{-0.91} R e_{n}^{-0.42}\end{array}$ \\
\hline$[21,29,30]$ & $\begin{array}{l}\text { Co-current pulsed } \\
\text { column }\end{array}$ & $\begin{array}{l}\text { Several } \\
\text { minutes }\end{array}$ & - Low viscosity & $\begin{array}{l}\text { Vertical COBR } \\
\text { Riser } \\
\frac{d_{32}}{D}=0.40( \pm 54 \%) R e_{o}^{-0.57( \pm 17.72 \%)} R e_{n}^{0.31( \pm 12.25 \%)} \\
\text { Downcomer } \\
\frac{d_{32}}{D}=1.24( \pm 41.9 \%) R e_{o}^{-0.66( \pm 10.9 \%)} \operatorname{Re}_{n}^{0.27( \pm 15.65 \%)} \\
\text { Horizontal COBR } \\
\frac{d_{32}}{D}=107 \operatorname{Re}_{o}^{-0.9} \operatorname{Re}_{n}^{0.13} \\
\sigma: 20.5 \mathrm{mN} \mathrm{m}^{-1}, \rho_{d} / \rho_{c}: 0.92, \mu_{d} / \mu_{c}: 5, \Phi: 5-20 \% \text { vol. } \\
\text { Disc and doughnut pulsed column } \\
d_{32} / D=5 \operatorname{Re}_{o}^{-0.85} \mathrm{We}^{-0.26} \\
\sigma: 3.5 \mathrm{mN} \mathrm{m}^{-1}, \rho_{d} / \rho_{c}: 0.87, \mu_{d} / \mu_{c}: 0.59, \Phi: 25-40 \% \text { vol. }\end{array}$ \\
\hline$[19,31]$ & Rotor-stator & $0.1-1 \mathrm{~s}$ & $\begin{array}{l}\text { - Optimal range of viscosity } 20- \\
5000 \mathrm{mPa}\end{array}$ & $\begin{array}{l}\frac{d_{32}}{D}=0.201\left(\frac{\mu_{d}}{\mu_{c}}\right)^{0.066} W e^{-0.6} \\
\sigma: 8.9-12.7 \mathrm{mN} \mathrm{m}^{-1}, \rho_{d} / \rho_{c}: 0.93-0.97, \mu_{d} / \mu_{c}: 9.7-969, \Phi: 5-50 \% \\
\text { vol. }\end{array}$ \\
\hline [19] & High pressure & $0.1-3 \mathrm{~ms}$ & - Optimal range of viscosity $1-200 \mathrm{mPa}$ & - \\
\hline
\end{tabular}

reactors to carry out the reaction in a continuous pathway. To satisfy the requirements expected in suspension polymerization, all the droplets must experience narrow range of shear rates or energy dissipation rate. Moreover, the equipment must respond to industrial constraints, ensuring compatibility and flexibility. Considering the initial liquid-liquid dispersion static mixers or pulsed column are potential candidates.

In the two reactive steps, the main bottleneck is the reactor plugging due to an uncontrolled droplets agglomeration or induced by the wall interaction. For the batch to continuous transposition, plug-flow reactor can be considered. The open literature is relatively poor on the continuous suspension polymerization. Some anecdotic cases are reported about continuous stirred tank reactors and tubular reactors [32]. More works report on continuous emulsion polymerization in pulsed column [9,33]. Authors highlight the efficiency of pulsation to prevent fouling. At lab scale, batch oscillatory baffled reactors have been used to carry out suspension polymerization $[6,34,35]$. These reactors are available in a continuous configuration, named continuous oscillatory baffled reactor COBR. The present study is an attempt to study liquid-liquid dispersion and perform suspension polymerization in COBR.

The batch configurations have been extensively described in literature [6,34-41]. Table 2 lists the different parameters affecting droplet size and the correspondent correlations for oscillatory baffled reactor in batch. Pulsation seems to be relevant to control droplet size and to obtain narrow droplet size distribution. However, to our knowledge only the work of $\mathrm{Ni}$ and co-workers $[29,30,42,43]$ refer to liquid-liquid dispersion in continuous oscillatory baffled reactor in which a classical water/oil system is studied without surfactant. COBR are used to carried out continuous-flow heterogeneous reactions such as heterogeneous catalysis reaction [44], biodiesel production [45] or crystallization [46]. Their use as polymerization reactor is mentioned [35] but never described in literature.

In this work, a focus is made on the liquid-liquid dispersion in continuous oscillatory baffled reactor. The different process parameters (flow rate, oscillation conditions) and the effect of the dispersed phase hold-up are reviewed. A correlation is proposed to estimate the mean droplet size. The required reactor length to obtain the liquid-liquid dispersion is then defined. A brief perspective of its use as suspension polymerization reactor is finally described to produce poly(vinyl acetate) PVAc. It is used to produce PVA (polyvinyl alcohol, vinyl acetate polymer partially hydrolyzed) by saponification. It is mainly used as wood glue and provides some medicine applications for tumour embolization $[47,48]$.

Table 2

Liquid-liquid dispersion in batch oscillatory baffled reactor.

\begin{tabular}{|c|c|c|c|}
\hline & & Studied effect & Consequences \\
\hline$[38]$ & Batch OBR & Oscillation & $d_{32} \approx\left(x_{0} f\right)^{-1.2}$ \\
\hline$[38,41]$ & & Surfactant concentration & $\begin{array}{l}\text { - No effect on the stabilization time } \\
\text { - Narrow DSD and } d_{32} \text { at lower interfacial tension }\end{array}$ \\
\hline$[41]$ & & Dispersed phase holdup & $\begin{array}{l}10-70 \% \\
\text { No mention of droplet size } \\
\text { Same oscillation conditions for complete dispersion }\end{array}$ \\
\hline$[36,38,41]$ & & Baffle thickness and species & $\begin{array}{l}\text { - Thickness of } 3 \mathrm{~mm} \text { is optimum for dispersion stabilization } \\
\text { - Decrease of the transparency factor } T \text {, decrease of } d_{32}\end{array}$ \\
\hline
\end{tabular}


PVAc is mainly produced by emulsion polymerization but few publications deal with VAM (vinyl acetate monomer) suspension polymerization [49-51].

\section{Experimental section}

\subsection{Chemicals}

Technical grade of toluene (95\% of purity) and vinyl acetate monomer (VAM) inhibited by $10-23 \mathrm{ppm}$ of hydroquinone were respectively purchased from Gaches Chimie and Sigma Aldrich and used without further purification. The stabilizer used in this study was the poly(vinyl acetate) partially hydrolyzed (88\%) provided by Nippon Gohsei company. The thermal initiator involved in the suspension polymerization was the Peroxan BCC (bis(4tert-butyl-cyclohexyl)-peroxidicarbonate)) supplied by Pergan. Distilled water was used.

\subsection{Liquid-liquid dispersion system}

For the study of liquid-liquid dispersion in the continuous oscillatory baffled rector (COBR), the water/surfactant/system used was the water/PVA/toluene system. The different component characteristics are described in Table 3.

The interfacial tension was measured by the pendant drop method (Krüss DSA 100).

The viscosity measurement was determined by using a AR 2000 rheometer (TA instrument).

\subsection{Suspension polymerization recipe}

The initiator concentration was set to $0.1 \%$ molar based on the VAM concentration. The surfactant concentration was fixed at $2000 \mathrm{ppm}$. The initiator consisted of white powder non soluble in water. A premix was prepared composed by demineralized water, PVA suspending agent and the initiator. A rotor-stator enabled the homogenization of the mixture. For these experiments, the dispersed phase concentration of the initial VAM dispersion was of $16 \%$ wt. in order to prevent from additional difficulties related to concentrated systems, and especially the clogging of the reactor.

The different phases were degassed by using nitrogen flux to avoid oxygen introduction which acts as polymerization inhibitor. In order to scavenge the radicals and to prevent polymerization, hydroquinone from Sigma Aldrich was purchased to inhibit the polymerization of the collected samples.

\subsection{Experimental rig}

The different experimental set-ups are described in Fig. 2. The oscillatory baffled reactor was made of borosilicate glass tubes. The straight section was $700 \mathrm{~mm}$ long and $15 \mathrm{~mm}$ of internal diameter, $D$. The glass baffles were spaced from $26 \mathrm{~mm}$ (plus or minus $1 \mathrm{~mm}$ ) and left an annular opening $D_{o}$ of $8 \mathrm{~mm}$. There were 23 baffles per section. Every four straight sections, a U-shape section was connected. This U-shape section was $250 \mathrm{~mm}$ long and

Table 3

Physicochemical properties of the liquid-liquid system.

\begin{tabular}{ll}
\hline & Water/PVA/toluene \\
\hline$\rho_{c}\left(\mathrm{~kg} \mathrm{~m}^{-3}\right)$ & 997 \\
$\rho_{d}\left(\mathrm{~kg} \mathrm{~m}^{-3}\right)$ & 870 \\
$\mu_{c}(\mathrm{~Pa} \mathrm{~s})$ & 0.0059 \\
$\mu_{d}(\mathrm{~Pa} \mathrm{~s})$ & 0.001 \\
Surfactant concentration & $0.07 \%$ mass $/ \mathrm{kg}$ toluene \\
$\sigma_{e}\left(\mathrm{mN} \mathrm{m}^{-1}\right)$ & 3.5 \\
\hline
\end{tabular}

the glass baffled spacing was of $31 \mathrm{~mm}$. The transparency factor $T$, defined expression 1 , was then equal to $28 \%$.

$T=\left(\frac{D_{o}}{D}\right)^{2}$

On the right size, the $U$ sections were on the same plane whereas on the left side, the $U$ tubes were perpendicular to the horizontal plane and then the flow is upward. The sections were jacketed except the U-tube. Consequently, the flow is largely in the horizontal direction with an ascendant movement due to the tubes connections (Fig. 2).

Two configurations were used and described in this paper. In the main part of the paper devoted to the liquid-liquid dispersion study, a length of $5.15 \mathrm{~m}$ was used as reactor. Fig. 2a describes the different inlets of the reactors. The temperature was set between 20 and $23^{\circ} \mathrm{C}$. The inlets of the aqueous and organic phases were ensured by two gear pumps with flow rate ranging from 15 to $150 \mathrm{~g} \mathrm{~min}^{-1}$. The pumps were equipped with check valves to avoid the backward of the flow. The pulsation was performed by using a piston connected at the basis of the first section. The oscillation amplitudes ranged from 10 to $70 \mathrm{~mm}$ and the pulsation frequency from 0.35 to $1.4 \mathrm{~Hz}$. The regulation was made thanks to the command panel.

On each feeding lines, a temperature sensor, a flow meter and a densimeter were implemented in order to register their temporal evolution. The set-point flow rate was entered and a PID regulator controlled the valve opening for regulating the flow rate. Due to the oscillation, the flow rate fluctuated with an error inferior to $2 \%$.

For the liquid-liquid dispersion study, sampling valves were installed at different sections of the reactor in order to measure the droplet size distribution and the mean droplet size along the reactor. At the COBR outlet, the on-line Turbiscan ${ }^{\circledR}$ measurement cell was set to follow the steady-state flow and to measure the mean Sauter diameter.

For the polymerization study, Fig. 2b describes the introduction of the three phases (water, premix and vinyl acetate monomer) and the different operating sections of the reactors respectively devoted to the phases introduction, the liquid-liquid dispersion creation and the reaction step. To prevent thermal runaway of the reaction, additional sensors were set to control the temperature. The different placements of the sensors (PT100) and sampling valves for conversion and particle analysis are depicted on the Fig. 2b. Table 4 sums up their locations as well as the length devoted to each step.

The premix was fed by a piston HPLC pump (ARMEN) and was maintained under continuous stirring and nitrogen. The vinyl acetate was surrounded by a nitrogen blanket.

For the polymerization tests, the total flow rate was equal to $145.5 \mathrm{~g} \mathrm{~min}^{-1}$, corresponding to a total residence time of about $45 \mathrm{~min}$, including $30 \mathrm{~min}$ for the polymerization reaction. The pulsation conditions had been set according to the liquid-liquid study. Let's underline that the COBR was also equipped with a pressure sensor for safety reason and as soon as 5 bar were reached, the pulsation stopped. So the operating conditions must not exceed 4 bar.

\subsection{Analytical aspects}

\subsubsection{Droplet and particle size}

Two analysis apparatus were used to determine the droplet size: an off-line measurement and an on-line measurement.

The off-line measurement (Mastersizer 2000, Malvern) provided mean droplet size and droplet size distribution through laser diffraction. A large range of measurement is covered: from 0.02 to $2000 \mu \mathrm{m}$. Measurement of the droplet size distribution is based on the Mie diffraction theory. Some characteristic diameters can be 

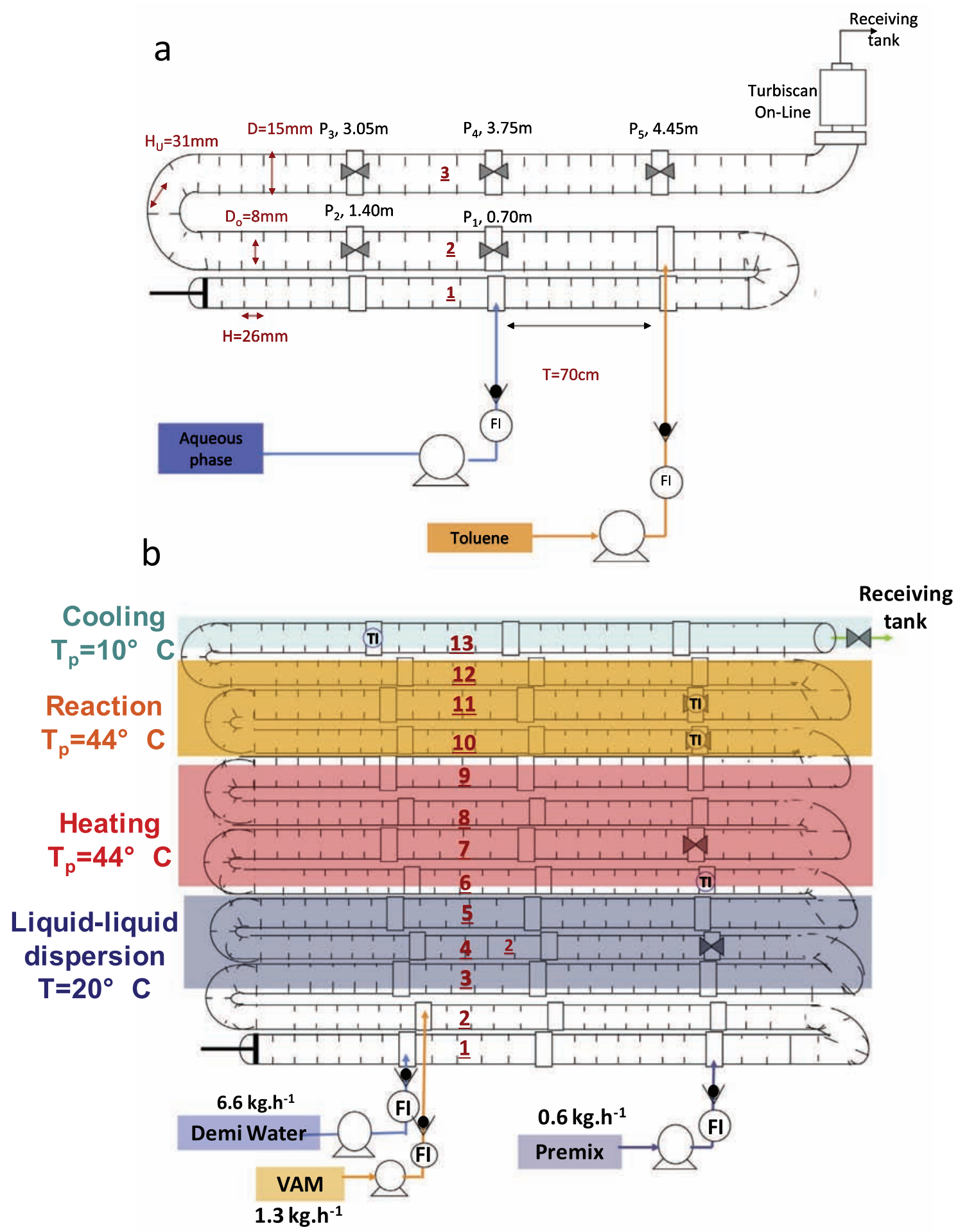

Fig. 2. Experimental set-up of the column (a) for the liquid-liquid dispersion study (b) for the polymerization tests with FI corresponding to flow controller and TI to the PT100 probe for temperature.

calculated from this measurement. For future discussion, it is relevant to define the mean Sauter diameters $d_{32}(2)$ and the span which quantifies the width of the distribution (3).

$$
d_{32}=\frac{\sum_{i=1}^{n} n_{i} d_{i}^{3}}{\sum_{i=1}^{n} n_{i} d_{i}^{2}}
$$

where $n_{i}$ is the number of droplets which sizes range from $d_{i}$ to $d_{i+1}$. span $=\frac{d_{90}-d_{10}}{d_{50}}$

The $d_{90}, d_{10}$ represent respectively the highest diameter of $90 \%$ in volume of the dispersed phase and the highest diameter of $10 \%$ in volume of the dispersed phase, while $d_{50}$ is the median diameter of the distribution i.e. the highest diameter of $50 \%$ in volume of the dispersed phase. These characteristic diameters are directly derived from the laser diffraction analyses. 
Table 4

Sample and measurement in course of polymerization $-H=0 \mathrm{~m}$ corresponds to the three phases (water, premix and oil) contact level.

\begin{tabular}{lll}
\hline & Position of the PT100 & Location of the sampling \\
\hline Phases introduction & & Total length (m) \\
Liquid-liquid dispersion & Section $6, H=10.8 \mathrm{~m}$ & P1: section $4, H=4.7 \mathrm{~m}$ \\
Reaction - heating & Section $10, H=23 \mathrm{~m}$ & P2: section $7, H=15.25 \mathrm{~m}$ \\
Reaction & Section $11, H=27.45 \mathrm{~m}$ & P3: section $10, H=23 \mathrm{~m}$ \\
Reaction - cooling & Section $13, H=32,15 \mathrm{~m}$ & P4: section $11, H=27.45 \mathrm{~m}$ \\
& & P5: outlet, $H=34.25 \mathrm{~m}$ \\
\hline
\end{tabular}

The on-line measurement was provided by the on-line Turbiscan (Formulaction) and gave access to the Sauter mean diameter $d_{32}$ without dilution. It is based on the light backscattering theory for which principle is described in literature [52,53].

Liquid-liquid dispersions were analyzed by optical microscopy (Zeiss AXIO Observer A1m) after dilution of the sample.

For the particles observation, scanning electron microscopy (SEM Hitachi TM 3000) was used. The SEM technique gives access to the surface and the shape of the poly(vinyl acetate) particles obtained.

\subsubsection{Conversion measurement}

Conversion was deduced from gravimetric analysis. It consists in weighting the sample prior and after the vacuum drying. Knowing the initial monomer loading, the conversion can be calculated.

\section{Liquid-liquid dispersion in a continuous oscillatory baffled reactor (COBR)}

\subsection{Background}

The instantaneous velocity of liquid in a pulsatile flow contains two components: a permanent flow velocity $U_{0}$ characterizing the flow rate and a pulsed one due to pulsation $U_{p}(t)$.

$U(t)=U_{0}+U_{p}(t)$

The pulsation velocity created by a piston mechanical device can be expressed by (5):

$U_{p}(t)=\pi A f \cos (2 \pi f t)$

where $A$ is the oscillation amplitude which characterize the fluid displacement inside the column and $f$ is the oscillation frequency.

The mean flow velocity is then defined as:

$U_{m}=U_{0}+U_{p m}$

where the mean oscillation velocity $U_{p m}$ is expressed by

$U_{p m}=\frac{1}{T} \int_{0}^{T} U_{p}(t) d t=2 A f$

Consequently, two different Reynolds numbers are usually defined to characterize the flow in such pulsed column:

- the net flow Reynolds number which is related to the net flow velocity

$R e_{n}=\frac{U_{0} D}{v}$

- the oscillatory Reynolds number which is defined in accordance with the pulsatile component of the flow

$\operatorname{Re}_{0}=\frac{2 A f D}{v}$

$v$ is the kinematic viscosity and $D_{\mathrm{c}}$ is a characteristic diameter of the column.
In pulsed flow, an inversion of the flow occurs at every half period because $U_{p m} / U_{0}$ is superior to 1 [40]. According to the operating conditions (Table 5), it ranges from 1.7 to 8.3.

\subsection{Operating conditions}

Table 5 covers the different parameters investigated in this section: throughput, pulsation conditions (amplitude, frequency) and dispersed phase hold-up.

The holdup $\Phi$ is defined by:

$\Phi=\frac{Q_{d}}{Q_{d}+Q_{c}}$

It assumes that there is no slip velocity. The studied flow rates were chosen to avoid particles sedimentation in course of polymerization reaction. The calculation is based on a $150 \mu \mathrm{m}$ particles for $40 \%$ vol. of dispersed phase holdup $\Phi$. The range of pulsation conditions is set by the pilot. The repeatability has been checked (see ESI, Fig. S1).

\subsection{Evolution of the mean droplet size and droplet size distribution along the COBR}

In multi steps reactor like the COBR, the length of the reactor devoted to each step must be optimized to reduce the space requirement. Concerning liquid-liquid dispersion step, the optimum length is defined as the required length to reach and stabilize the droplet size. As a consequence, the droplet size distribution and the mean droplet size evolution at different axial positions of the column were measured in different process conditions (flow rate and oscillation conditions).

Different behaviors of the liquid-liquid dispersion were observed depending on the pulsation conditions. Three cases can be distinguished and are depicted in Fig. 3. Oscillation conditions affect strongly the droplet size distribution stabilization. In Fig. 3a, the droplet size distributions are shifted to the larger size along the reactor leading to an increase of the mean droplet size along the column. On the contrary, in Fig. 3b, the droplet size distributions are almost superimposed and the mean droplet size is maintained for all the axial position sampling. Besides, it seems that the droplet size distribution becomes narrower along the column. A halfway case can be noticed. In Fig. 3c, the droplet size distributions are first become narrower and provide smaller sizes from 3.05 m length.

From the different oscillation conditions tested (Table 5), a mapping of the stability efficiency along the column was drawn. Fig. 4 describes the conditions suitable for stable liquid-liquid dispersion.

Fig. 4 is interesting for the future polymerization tests presented in the Section 4. For the further results, the mean droplet size evolution and modeling will be performed while considering the value of the droplet size at $4.45 \mathrm{~m}$.

Fig. 5 highlights the previous results by confirming mean droplet size tendency depending on the pulsation conditions. The sam- 
Table 5

Operating conditions in the continuous oscillatory baffled reactor.

\begin{tabular}{|c|c|c|c|c|c|c|}
\hline $\begin{array}{l}\Phi \\
\text { (\%vol.) }\end{array}$ & $\begin{array}{l}Q_{t o t} \\
\left(\mathrm{~L} \mathrm{~h}^{-1}\right)\end{array}$ & $Q_{\text {toluene }}\left(\mathrm{g} \mathrm{min}^{-1}\right)$ & $Q_{\text {aqueous phase }}\left(\mathrm{g} \min ^{-1}\right)$ & $\begin{array}{l}x_{0} f \\
\left(\mathrm{~mm} \mathrm{~s}^{-1}\right)\end{array}$ & $x_{0}(\mathrm{~mm})$ & $f(\mathrm{~Hz})$ \\
\hline \multirow[t]{2}{*}{25} & 7.63 & $\begin{array}{l}27.70 \pm 0.40 \mathrm{~g} \mathrm{~min}^{-1} \\
( \pm 1.43 \%)\end{array}$ & $95.10 \pm 0.54 \mathrm{~g} \mathrm{~min}^{-1}( \pm 0.6 \%)$ & $14-50$ & $10-20-30-40-50$ & $\begin{array}{l}0.35-0.50-0.75-1.00-1.25- \\
1.40\end{array}$ \\
\hline & 10.18 & $\begin{array}{l}39.90 \pm 0.70 \mathrm{~g} \mathrm{~min}^{-1} \\
( \pm 1.90 \%)\end{array}$ & $\begin{array}{l}126.90 \pm 1.48 \mathrm{~g} \mathrm{~min}^{-1} \\
( \pm 1.17 \%)\end{array}$ & $14-50$ & $\begin{array}{l}10-15-20-25-30-35-40- \\
50\end{array}$ & $0.50-0.75-1.00-1.25-1.40$ \\
\hline \multirow[t]{3}{*}{40} & 7.63 & $\begin{array}{l}44.30 \pm 0.26 \mathrm{~g} \mathrm{~min}^{-1} \\
( \pm 0.60 \%)\end{array}$ & $76.30 \pm 0.60 \mathrm{~g} \mathrm{~min}^{-1}( \pm 078 \%)$ & $10-50$ & $\begin{array}{l}10-15-20-25-30-35-40- \\
50\end{array}$ & $0.35-0.75-1.00-1.25-1.40$ \\
\hline & 10.18 & $\begin{array}{l}59.04 \pm 0.50 \mathrm{~g} \mathrm{~min}^{-1} \\
( \pm 085 \%)\end{array}$ & $\begin{array}{l}101.50 \pm 1.01 \mathrm{~g} \mathrm{~min}^{-1} \\
( \pm 0.99 \%)\end{array}$ & $10-50$ & $\begin{array}{l}10-15-20-25-30-35-40- \\
50\end{array}$ & $\begin{array}{l}0.35-0.50-0.75-1.00-1.25- \\
1.40\end{array}$ \\
\hline & 12.69 & $\begin{array}{l}73.60 \pm 0.30 \mathrm{~g} \mathrm{~min}^{-1} \\
( \pm 0.41 \%)\end{array}$ & $\begin{array}{l}126.50 \pm 1.37 \mathrm{~g} \mathrm{~min}^{-1} \\
( \pm 1.09 \%)\end{array}$ & $15-37.5$ & $15-20-25-30-35-40$ & $0.75-1.00-1.25-1.40$ \\
\hline
\end{tabular}
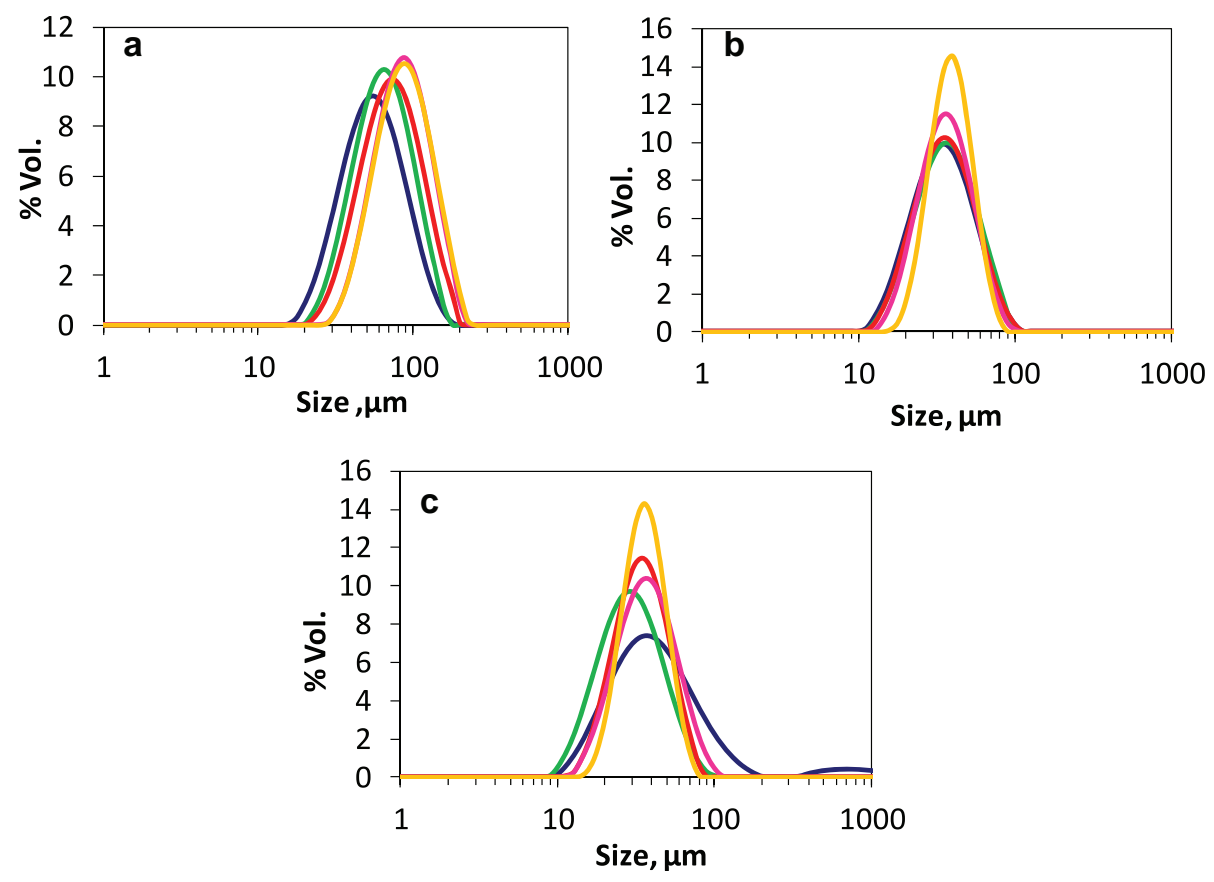

Fig. 3. Droplet size distribution all along the column for different operating conditions for different axial positions (a) $Q_{\text {tot }}=10.1 \mathrm{~L} \mathrm{~h}{ }^{-1}, x_{0}=20 \mathrm{~mm}, f=0.75 \mathrm{~Hz}, \Phi=25 \%$, (b) $Q_{\text {tot }}=10.3 \mathrm{~L} \mathrm{~h}^{-1}, x_{0}=35 \mathrm{~mm}, f=1 \mathrm{~Hz}, \Phi=25 \%$ and (c) $Q_{\text {tot }}=10.35 \mathrm{~L} \mathrm{~h}^{-1}, x_{0}=25 \mathrm{~mm}, f=1.4 \mathrm{~Hz}, \Phi=25 \%$. Blue solid line: $H=0.70 \mathrm{~m}$, green solid line: $H=1.40 \mathrm{~m}$, red solid line: $H=3.05 \mathrm{~m}$, pink solid line: $H=3.75 \mathrm{~m}$ and orange solid line: $H=4.45 \mathrm{~m}$. (For interpretation of the references to colour in this figure legend, the reader is referred to the web version of this article.)



Fig. 4. Mapping of the dispersion stabilization on all the tests performed: $*$ : stable dispersion : unsuitable conditions.

ple corresponding to $H=5.15 \mathrm{~m}$ is obtained by on-line Turbiscan measurement set at the COBR outlet.

The effect of the operating conditions and hold-up are independently studied.

\subsection{Effect of the operating conditions}

\subsubsection{Effect of the total net flowrate in the COBR}

Here the presented results concern a dispersed phase concentration $\Phi$ of $40 \%$ vol. The same oscillation conditions were tested in three total flow rate conditions corresponding to three, four and five times the terminal velocity for a polymer particle of $150 \mu \mathrm{m}$. Indeed, as described in Fig. 1, initial emulsion of 30$50 \mu \mathrm{m}$ of mean droplet size lead to polymer beads or pearls of $150 \mu \mathrm{m}$ mean particle size.

The effect of the flow rate is expressed as net flow Reynolds number $R e_{n}$ expressed in Eq. (8) and the pulsation conditions are defined by the dimensionless $\operatorname{Re}_{o}$ (expression (9)). Whatever the pulsation conditions, it appears that the mean Sauter diameter is insensitive to the net flow rate in the tested operating conditions and considering the measurement uncertainties (Fig. 6). This result is consistent with the literature results [54-57] for different pulsed columns but is not in accordance with previous COBR studies $[29,30]$ (Table 1 ). In these studies [29,30], no surfactant was added to the aqueous phase. Moreover the net flow Reynolds number played a significant role in vertical column described in Pereira 


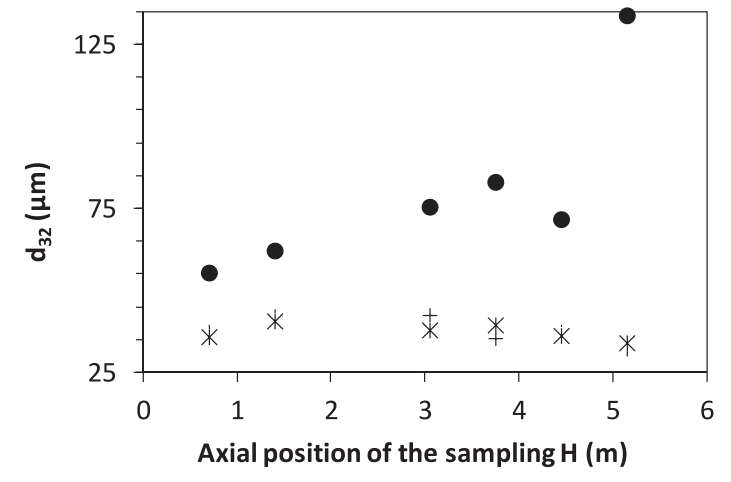

Fig. 5. Evolution of the mean Sauter diameter in different operating conditions all along the column (oscillation velocities: - $15 \mathrm{~mm} \mathrm{~s}^{-1}+$ : $30 \mathrm{~mm} \mathrm{~s}^{-1}$, *: $\left.37.5 \mathrm{~mm} \mathrm{~s}^{-1}\right), Q_{\text {tot }}=7.62 \mathrm{~L} \mathrm{~h}^{-1}, \Phi=25 \%$.

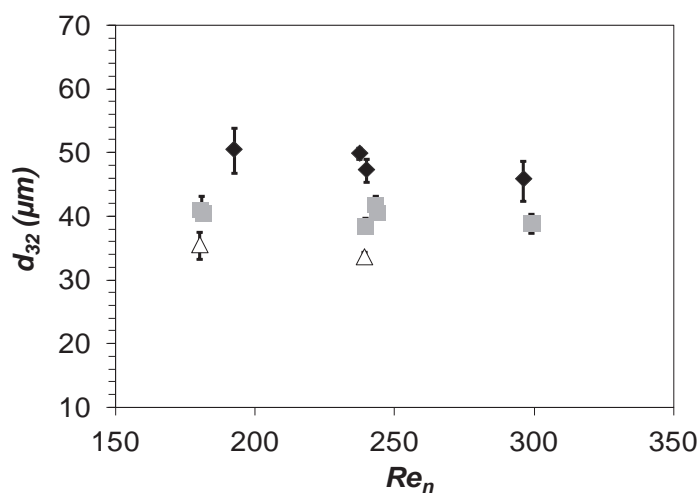

Fig. 6. Mean Sauter diameter dependence to the net flow Reynolds number $R e_{n}$ at different pulsation conditions $\left(R e_{0}=1797, \square R e_{o}=2096, \triangle R e_{o}=2989\right)$ for a dispersed phase holdup $\Phi=40 \%$.

and $\mathrm{Ni}[30]$ with a power law exponent around 0.3. In horizontal COBR, the dependence is considered to be negligible with an exponent equal to 0.13 .

Moreover, on the opposite, the Sauter diameter is affected by the oscillation conditions. Indeed, at same $R e_{n}$, the Sauter mean diameter obtained decreases whereas the oscillatory Reynolds number $\operatorname{Re}_{o}$ increases.

\subsubsection{Effect of the oscillating conditions}

Both effects of the amplitude and of frequency have been evaluated independently.

3.4.2.1. Effect of the amplitude. The amplitude effect on the mean Sauter diameter and droplet size distribution (DSD) is investigated at a constant net flow Reynolds number $\left(R e_{n}=241\right)$ and for different frequencies.

An increase of the oscillation amplitude $A$ reduces the mean Sauter diameter value $d_{32}$ as depicted in Fig. 7a. This result is in accordance with previous work [29] which suggests a -0.76 exponent. This tendency was expected since the amplitude is related to the mean energy dissipation rate and consequently to the turbulent intensity involved in the breakage mechanism.

3.4.2.2. Effect of the frequency. The second component of the oscillation conditions is the frequency $f$. In the same way, increasing the frequency enables the decrease of the mean Sauter diameter $d_{32}$ (Fig. 8). The mean droplet size is proportional to the frequency with a power law exponent of -0.92 . This result matches with

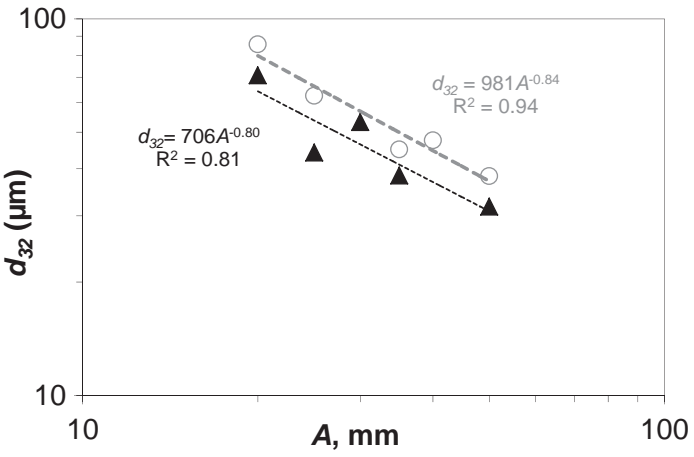

Fig. 7. Effect of the amplitude on the mean droplet size $R_{n}=241 \Phi=25 \%$ ( $\Delta$ : $f=1 \mathrm{~Hz}$ and $\bigcirc: f=0.75 \mathrm{~Hz}$ ).

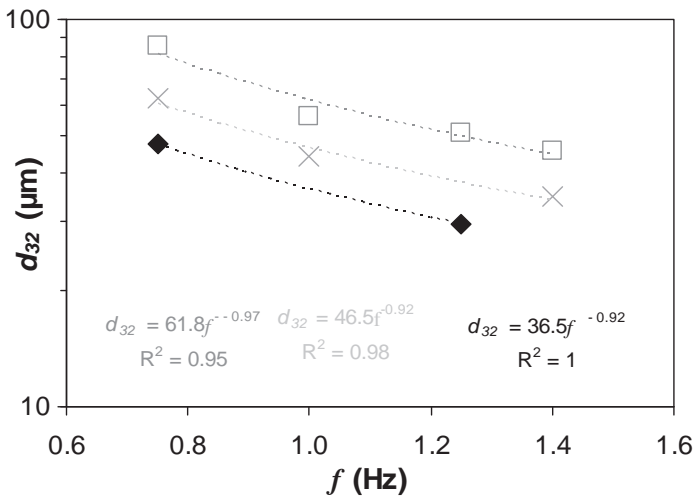

Fig. 8. Mean Sauter diameter as a function of the oscillation frequency at fixed amplitude and same $R e_{n}=241$ and dispersed phase holdup $\Phi=25 \%$ ( $\square: f=\mathrm{Hz}, \square$ : $f=\mathrm{Hz}, \diamond: f=\mathrm{Hz})$.

the Pereira [29] observations for horizontal continuous oscillatory baffled reactor which reported an exponent value of -0.85 .

3.4.2.3. Effect of the oscillating conditions: the oscillatory Reynolds number Reo. The results are finally correlated thanks to the oscillatory Reynolds number $\operatorname{Re}_{o}$ (9). Given the net flow Reynolds number $R e_{n}$ has no effect (Section 3.3.1.), the change in mean Sauter diameter according to $R e_{o}$ is presented in Fig. 9 for the two net Reynolds numbers $R e_{n}$ tested and for a dispersed phase holdup $\Phi$ of $25 \%$ vol.

The mean Sauter diameter follows a decreasing power law with the $R e_{o}$ according to expression (11).

$\frac{d_{32}}{D}=2.2 R e_{0}^{-0.9}$

The fitting is in agreement with the model proposed by Pereira [29] provided Table 1 . The characteristic dimension of both COBR, used in this study and in Pereira's study are depicted Table 6.

\subsection{Effect of the dispersed phase holdup}

Two dispersed phase holdups have been tested, respectively equal to $25 \%$ and $40 \%$ in volume. The other operating conditions (total net flow rate and oscillation conditions) are maintained constant. No significant effect of the holdup is noticed in the investigated range of the operating conditions. At same $R e_{n}$ and oscillation parameters $(A, f)$, the droplet size distributions are totally superimposed whatever the dispersed phase holdup (Fig. 10a). In the same way, the mean Sauter diameter droplet presents a similar pattern: the holdup has no significant effect on the 


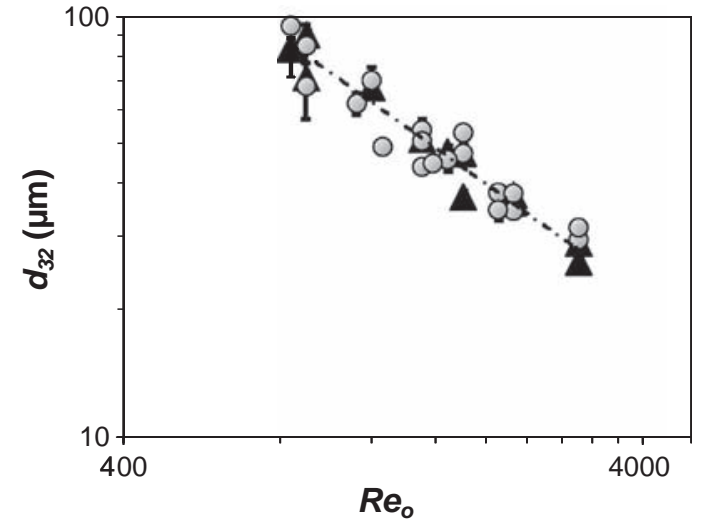

Fig. 9. Mean Sauter diameter in function of the oscillatory Reynolds number $R e_{o}$, $\Phi=25 \%$ for the two different $\operatorname{Re}_{n}(\Delta: 180$ and $\bigcirc: 241)$.

Table 6

Comparison of the Pereira (2002) [23] COBR and the COBR of this study.

\begin{tabular}{lll}
\hline & COBR of this study & COBR Pereira (2002) \\
\hline Column diameter $D(\mathrm{~mm})$ & 15 & 40 \\
Baffle hole $(\mathrm{mm}) D_{o}$ & 8 & 18 \\
Baffle spacing $H(\mathrm{~mm})$ & 26 & 72 \\
Baffle free area $\%$ & $28 \%$ & $21 \%$ \\
\hline
\end{tabular}

$d_{32}$ whatever the axial position in the tested conditions. (see Fig. 10b)

\subsection{Axial dispersion}

Some correlations are available in literature for axial dispersion in oscillatory baffled reactor of larger size [43]. Table 6 reminds the
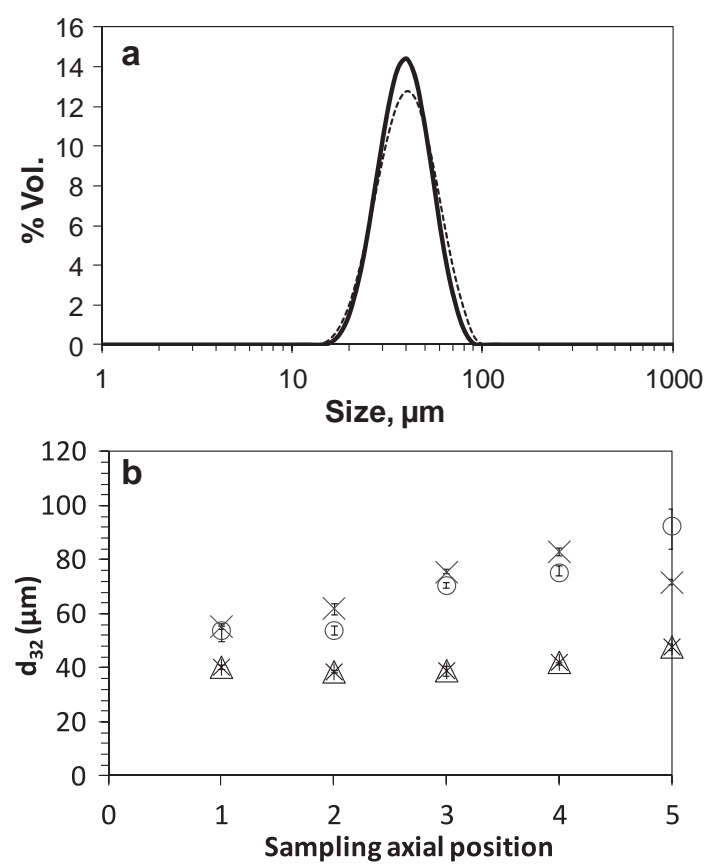

Fig. 10. (a) Droplet size distributions obtained at $R e_{n}=240, A=50 \mathrm{~mm}, f=0.75 \mathrm{~Hz}$ at the final axial position sampling at a dispersed phase holdup equal to $25 \%$ (solid line) and $40 \%$ (dotted line). (b) Evolution of the mean Sauter diameter with the axial position for different dispersed phase fraction, under two different oscillation conditions, $R e_{n}=180(20 \mathrm{~mm}, 1.4 \mathrm{~Hz}, *: 25 \% \Delta: 40 \%$ and $20 \mathrm{~mm}, 0.75 \mathrm{~Hz}, \square: 25 \%$, ○: $40 \%)$. geometrical characteristics of the reactors of this study and in the Pereira's study.

$\mathrm{Ni}$ et al. [37] compared the axial dispersion coefficient for different pulsed devices (close-fit, loose-fit baffle, Karr plate and multiperforated plate of various scales). They demonstrated that the axial dispersion coefficient is proportional to the mean energy dissipation rate and to the geometrical characteristics of the system, as follows:

$D_{a x} \propto L^{4 / 3} \varepsilon^{1 / 3} \propto(A f) D\left(\frac{h}{D}\right)^{1 / 3}\left(\frac{1-T^{2}}{T^{2}}\right)^{1 / 3}$

$D_{a x}$ is the axial dispersion in $\mathrm{m}^{2} \mathrm{~s}^{-1}, D$ is the internal diameter of the column ( $\mathrm{m}), h$ is the baffle spacing ( $\mathrm{m}$ ) and $T$ the transparency factor (see expression (1)). The authors investigated the correlation (12) with different pulsed columns and the proportionality coefficient between the two terms of the equation was found equal to 1.1 .

This correlation enables us to have an insight of the axial dispersion in the COBR. The Peclet number (or Bodenstein number), defined by the expression (13), characterizes the residence time distribution in a tubular reactor. It is defined as the ratio between total transfer and axial diffusion transfer.

$P e=\frac{u L}{D_{a x}}$

$L$ is the reactor length and $u$ the flow velocity.

In the investigated conditions, the corresponding Peclet numbers range from 30 to 100 . The plug flow conditions can be ensured from a Peclet number value of 40 . The Peclet lower values (ie, higher axial mixing coefficients) are obtained for the higher amplitudes.

\subsection{Modeling}

\subsubsection{Mean energy dissipation rate}

The results can be expressed in terms of mean energy dissipation rate. Given the hydrodynamic in oscillatory baffled reactor, two components can be considered due to the net flow $\varepsilon_{n}$ and the oscillatory flow $\varepsilon$.

The first term is the mean energy dissipation due to flow and baffles. The pressure drop in a baffled tube due to the net flow is defined by (14):

$\Delta P=N_{\text {tot }} \frac{\rho u^{2}}{2 C_{D}}\left(\frac{1}{T^{2}}-1\right)$

With $\Delta P$ the pressure drop in Pa, $u$ the flow velocity $\left(\mathrm{m} \mathrm{s}^{-1}\right), \rho$ the density of the flow, $N_{\text {tot }}$ the total number of baffle in the column and $T$ the fractional open area. $C_{D}$ is the standard orifice coefficient, usually taken at 0.6 .

The mean energy dissipation due to the net flow in the column can then be expressed as:

$\varepsilon_{n}=\frac{\Delta P u}{\rho L}$

The second term is the mean energy dissipation rate due to the oscillations for which different correlations are provided [21]. According to the investigated conditions, the correlation of Jealous and Johnson [58] has been used to calculate this term expressed by:

$\varepsilon=\frac{P}{\rho V}=\frac{16 \pi^{2} N}{3 C_{D}^{2}} \frac{\left(1-T^{2}\right)}{T^{2}}(A f)^{3}$

where $N$ is the number of baffled cells per unit length $\left(\mathrm{m}^{-1}\right), T$ fractional free area defined as $\left(\frac{D_{0}}{D}\right)^{2}$ where $D_{0}$ and $D$ are the orifice 
and tube diameter $(\mathrm{m})$ respectively and $C_{D}$ the orifice coefficient for the flow through the baffle hole and is assumed to be 0.6 for fully developed conditions.

The calculated net mean energy dissipation $\varepsilon_{n}$ is negligible compared to the mean energy dissipation induced by the oscillatory component of the flow (several hundred orders of magnitude). Therefore, the net mean energy dissipation is not taken into account in the following part.

The mean droplet size evolution follows a decreasing power law with the mean energy dissipation with an exponent of -0.29 (Fig. 11). The Kolmogorov's theory which suggests a -0.40 exponent is not checked. The discrepancy is presumably due to the non-perfect homogeneous and isotropic turbulence and to the role played by the inserts on the breakage phenomenon.

\subsubsection{Mean droplet size}

In the different publications concerning the COBR, the mean droplet size is classically expressed as a power law of the oscillatory Reynolds number and of the net flow Reynolds number. Given that no effect of the net flow Reynolds number was pointed out, the mean Sauter diameter is expressed as a function of the oscillatory Reynolds number only. Oscillations are the main parameters responsible for breakage as noticed by Mignard et al. [42].The mean Sauter diameter follows a decreasing power law with a -0.88 exponent.

Such correlations do not take into account the fluid properties involving in the dimensionless Weber number. It is usual to express the mean Sauter diameter as a function of the dimensionless Weber number. It represents the ratio between the inertial forces and the interfacial forces. It depends on the continuous phase physical properties and on the interfacial tension. To extend this correlation for different systems, the dimensionless Weber number is defined with the hydraulic diameter:

$W e_{h}=\frac{\rho_{c}(A f)^{2} D_{h}}{\sigma}$

As a consequence, the oscillatory Reynolds number is defined thanks to the hydraulic diameter $D_{h}$. The corresponding hydraulic diameter is in fact the orifice baffle diameter $D_{0}$. Correlation (Fig. 12) was obtained considering our data and the silicon/water system studied by Pereira $[29,30]$.

Finally, the correlation obtained is expressed by:

$\frac{d_{32}}{D_{h}}=2.99 R e_{o h}^{-0.89} W e_{h}^{-0.08}$

Some additional experiments with different systems will be useful to precise the exponent of the hydraulic Weber number and confirm the tendency.

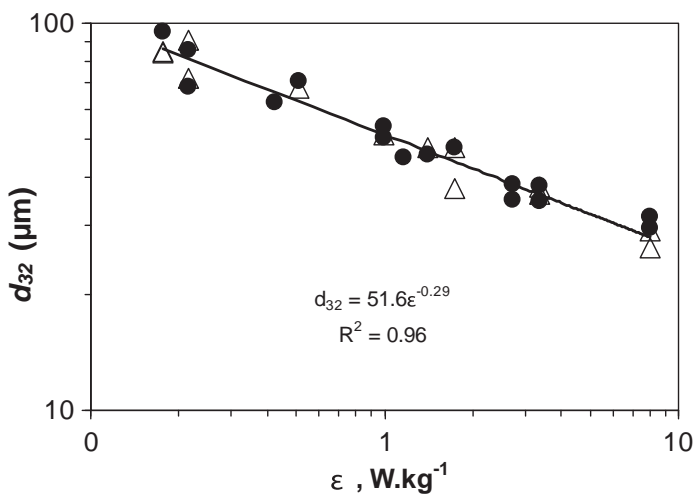

Fig. 11. Mean Sauter diameter as a function of the energy dissipation rate $(\triangle: 180$ and $\bullet$ : 241).

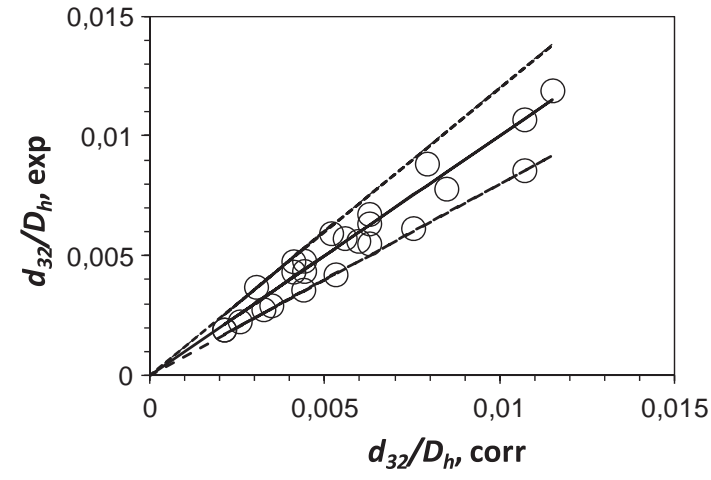

Fig. 12. Correlation of the mean Sauter diameter as function of dimensionless numbers ( $\bigcirc$ : experimental data, bold solid line: model, solid lines: error $\pm 20 \%$ ).

Table 7

Operating conditions for vinyl acetate monomer suspension polymerization.

\begin{tabular}{lll}
\hline & Test 1 & Test 2 \\
\hline$Q_{\text {VAM }}$ g min $^{-1}$ & 21.97 & 22.31 \\
$Q_{\text {demi water }}$ min $^{-1}$ & 111.24 & 111.56 \\
$Q_{\text {prémix }}$ g min & -1 \\
Initiator/VAM \%mol & 5.77 & 10.66 \\
PVAI/VAM ppm & 0.06 & 0.11 \\
Jacketed temperature section3-5 $\left({ }^{\circ} \mathrm{C}\right)$ & 1220 & 2250 \\
Jacketed temperature section $6-9\left({ }^{\circ} \mathrm{C}\right)$ & 22 & 22 \\
Jacketed temperature section $10-12\left({ }^{\circ} \mathrm{C}\right)$ & 61 & 61 \\
Jacketed temperature section $13\left({ }^{\circ} \mathrm{C}\right)$ & 56 & 56 \\
Amplitude $(\mathrm{mm})$ & 10 & 10 \\
Frequency $(\mathrm{Hz})$ & 30 & 30 \\
\hline
\end{tabular}



Fig. 13. Conversion $X$-time plot obtained by gravimetric measurement of the reactor outlet ( $\bigcirc$ Test $1, \Delta$ Test 2 ).

The goal of this work was to check whether it was possible to control the liquid-liquid dispersion step in the polymerization process thanks to a pulsed flow. The results are very encouraging and a suspension polymerization study can now be considered to prove the versatility of this reactor.

\section{Suspension polymerization of vinyl acetate monomer}

The PVAc is soluble in VAM [59]. The monomer dissolves its polymer and the monomer droplets exhibit a viscous syrup step to finally leading to solid clear little spheres called beads.

The goal of this suspension polymerization in continuous oscillatory baffled reactor is to demonstrate the feasibility of COBR as potential polymerization reactor. 


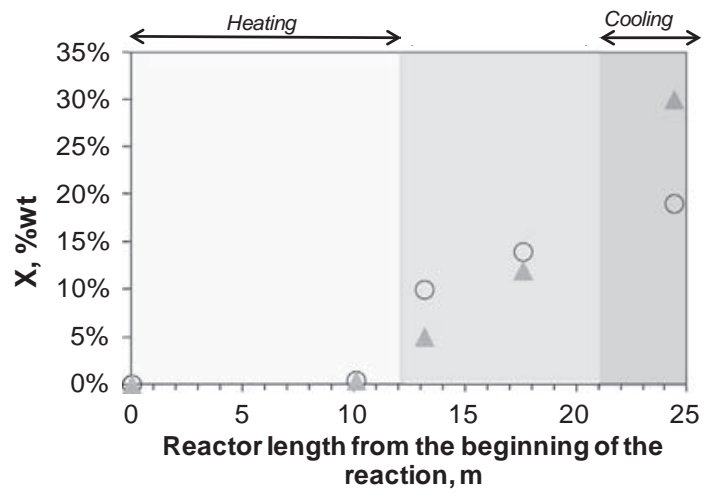

Fig. 14. Vinyl acetate monomer suspension polymerization conversion profile in the COBR ( $O$ Test $1, \Delta$ Test 2 ).

\subsection{Operating conditions}

The polymerization conditions are described in Table 7. The oscillation conditions have been defined in accordance with the previous tests to ensure stable liquid-liquid dispersion before polymerization and to minimize the pressure drop.

The vinyl acetate monomer polymerization is carried out by thermal radical suspension polymerization. The reaction kinetics depends on both temperature and initiator concentration. Temperature sensors were set at different axial positions (Table 4) and the temperature value of the reactive mixture was then recorded during the reaction. The temperature in the heating and polymerization sections was between 43 and $45^{\circ} \mathrm{C}$ during the experiments. So the heat loss was not negligible considering the double jacket temperature range between $61{ }^{\circ} \mathrm{C}$ and $55{ }^{\circ} \mathrm{C}$ in these sections of the COBR.

During a test, the reactor was filled of demineralized water. Then the vinyl acetate was introduced.

During the first 45 min no reaction occurred. After temperature and flow rate stabilization, the premix was introduced in the reactor.

The COBR was glass-made which leads to easy observation of the reactive media in course of polymerization the liquid-liquid dispersion and the polymerizing mixture were both opaque. No coating was applied on the glass wall contrary to batch stirred tank reactors in enamel or stainless steel usually used.

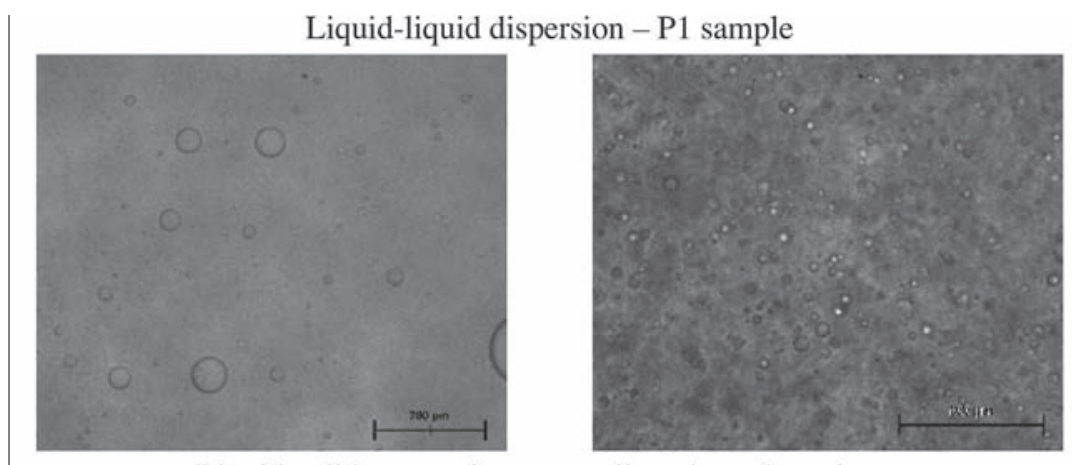

Liquid-solid suspension - sampling along the column

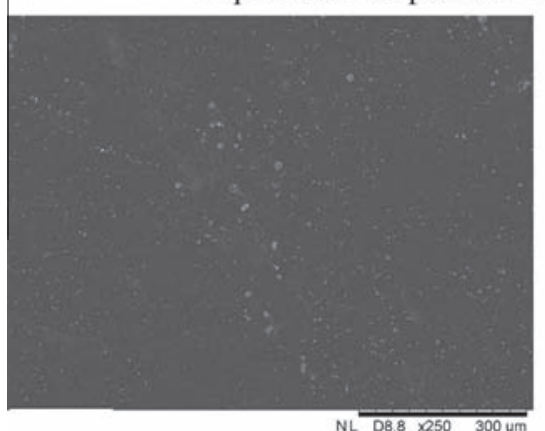

$\mathrm{P} 2-\mathrm{X}=0.41 \%$

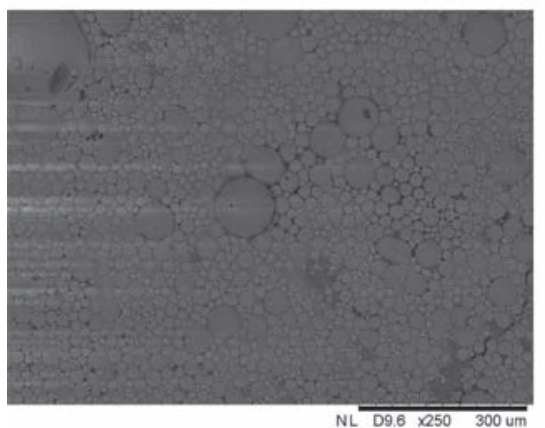

$\mathrm{P} 4-\mathrm{X}=14 \%$

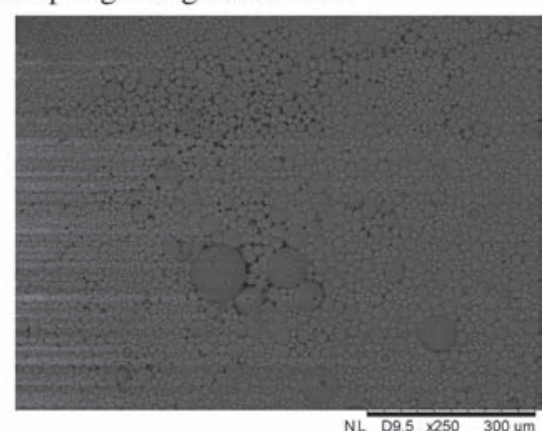

$\mathrm{P} 3-\mathrm{X}=10 \%$

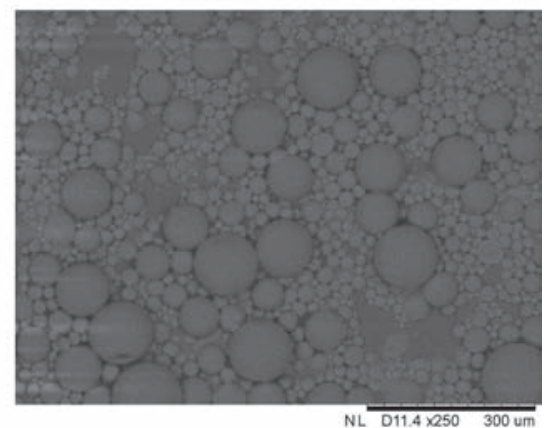

P5-reactor outlet-X=19\%

Fig. 15. Test 1 Microscopic pictures of the different samples: dispersion or polymerizing droplet at the different axial position of the column. 


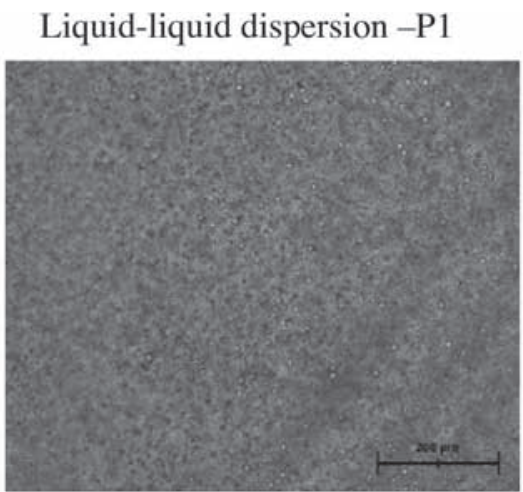

Liquid-solid suspension - sampling along the column
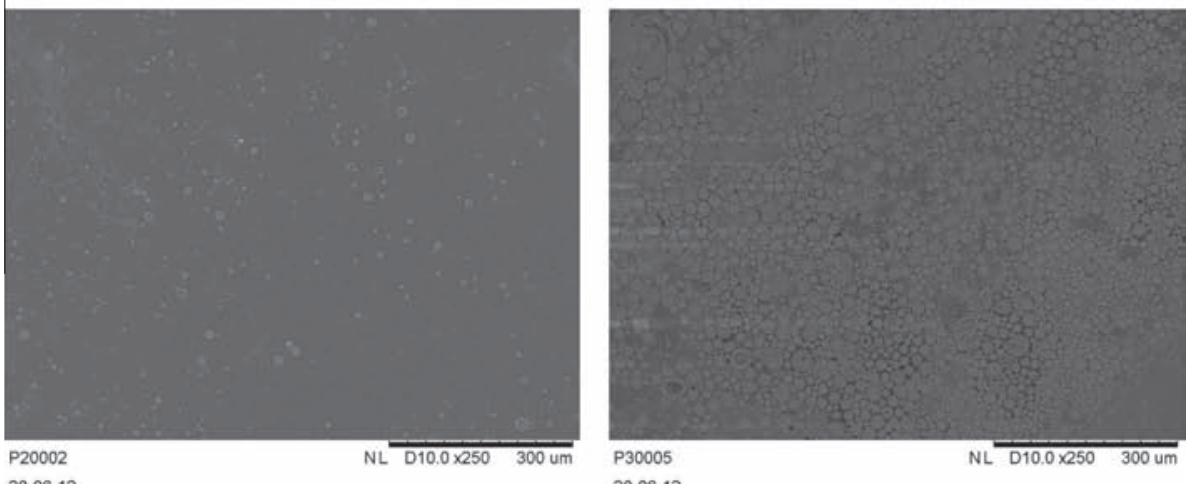

20-06-12

20-06-12

$\mathrm{P} 2-\mathrm{X}=0.4 \%$



NL. $\overline{09.7 \times 250 \quad 300 u m}$

$\mathrm{P} 4-\mathrm{X}=12 \%$



Fig. 16. Test 2 Microscopic pictures of the different samples: dispersion or polymerizing droplet at the different axial position of the column.

\subsection{Steady-state regime}

The time required to reach the stationary flow was evaluated. Samplings were collected at the COBR outlet to measure conversion. The conversion-time plot shows that the stationary regime was reached after $3 \mathrm{~h}$ (Fig. 13). Generally, after each sampling, the flow was disturbed and a degassing was observed from the Section 8.

Conversion $X$ is higher in the second test because of the higher amount of initiators (Table 7).

\subsection{Conversion along the reactor}

Once the permanent regime reached, the conversion profile depending on the axial position was evaluated by sampling at the different positions (Fig. 2b, Table 4). The conversion profiles obtained for the two tests are reported on Fig. 14.
Maximal conversions in the range $20-30 \%$ are reached. The reaction is partial but well-advanced to be in the agglomeration step where the particles exhibit a sticky behavior. So the COBR is efficient and effective to succeed in suspension polymerization.

The different samples were analyzed by SEM (Figs. 15 and 16). The particle evolution can be compared all along the column as well as the difference between the two tests. In test 1 , the liquid-liquid dispersion obtained seems to be multimodal: large drops are observed $(100 \mu \mathrm{m})$ on the left picture and very small droplets on the right picture. These larger droplets were not observed in the liquid-liquid dispersion of test 2. Less suspending agent (PVA) responsible for droplet stabilization were introduced in the Test 1 than in the Test 2. As a consequence, larger particles were also observed.

Concerning the second sample P2 located $12.2 \mathrm{~m}$ length after the contact of the three phases (Table 4), in both Figs. 15 and 16, the conversion is very low and dissymmetric particles were 

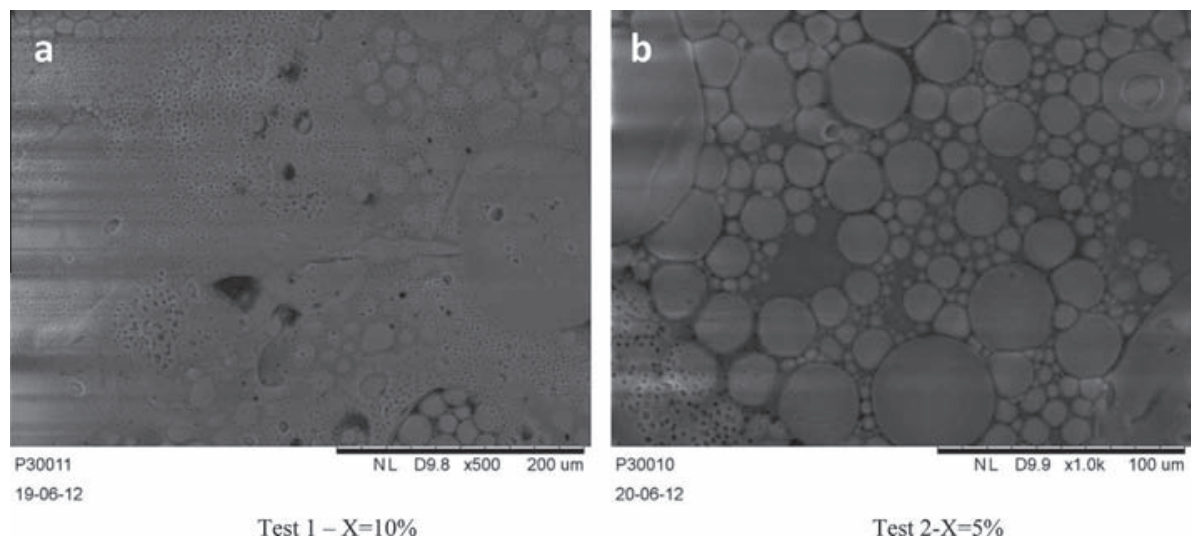

Fig. 17. Observation of the skin on the sample at low conversion for (a) Test 1 and (b) Test 2 (be careful both enlargements are different).

observed corresponding to initiator particles as confirmed by the analysis of a dried sample of liquid-liquid dispersion (see ESI, Fig. S2).

In course of polymerization, small particles were progressively created (samples P3 and P4, see Table 4, from Figs. 15 and 16). A film was observed which surrounded the particles as suggested by Fig. 17. From P3 to P5 (see Table 4 and Fig. 2b), the particle size did not evolve for a given test. In both cases, the polymerizing grains obtained were well spherical and mainly presenting a continuous and smooth aspect. As large droplets were created, large solid particles were also observed (Fig. 16). Additional pictures can be seen in the ESI (Fig. S3).

These first polymerization tests present very promising results for suspension polymerization of vinyl acetate.

\section{Conclusion}

The continuous oscillatory baffled reactor was selected to perform suspension polymerization. First, its ability to create controlled mean droplet size of narrow droplet size distribution was demonstrated. Liquid-liquid dispersion in COBR was thoroughly studied. The main parameter responsible for breakage is the oscillation velocity characterized by its oscillation amplitude and frequency product $A f$. Besides, at same pulsation conditions, the residence time can vary without effect on the dispersion properties. Both operating parameters can be adjusted independently to respectively control the residence time and the liquid-liquid dispersion characteristics which are the two key parameters of the process. Indeed in suspension polymerization, they fix the reaction time and the product characteristics. These sets of experiments enable the identification of the proper conditions for the polymerization tests. The feasibility tests were carried out with the vinyl acetate monomer and were very conclusive. The polymerization reached $30 \%$ of mass conversion. Some encrusting was observed on the reactor wall due to degassing in course of polymerization. The different operating parameters can now be investigated more deeply, in particular the temperature range, the suspending agent concentration or the initiator amount in order to optimize the suspension polymerization conversion and the pulsation conditions to identify the effect on particle size distribution. These preliminary tests provide however some encouraging results for the batch to continuous transposition of the suspension polymerization.

\section{Acknowledgements}

The authors would like to thanks the French National Agency (ANR) for its financial support.
Emeline Lobry wishes to thanks Alec Maunoury and Franck Dunglas for their precious help and their valuable advices. The authors would like to thanks Anne-Lise Conté, Sophie Cerdan and Sebastien Elgue for their welcome and the provision of the COBR at the MEPI (Maison Européenne des Procédés Innovants). The experimental facility was supported by the FNADT, Grand Toulouse, Prefecture Midi-Pyrenees and FEDER fundings.

\section{Appendix A. Supplementary data}

Supplementary data associated with this article can be found, in the online version, at http://dx.doi.org/10.1016/j.cej.2014.08.014.

\section{References}

[1] C. Gourdon, G. Casamata, Liquid Liquid Extraction Equipment, Godfrey and Slater, 1994.

[2] S. Charton, A. Kacem, A. Amokrane, G. Borda, F. Puel, J. Klein, Actinides oxalate precipitation in emulsion modeling: from the drop scale to the industrial process, Chem. Eng. Res. Des. 91 (2013) 660-669.

[3] R.J. Davey, A.M. Hilton, J. Garside, Crystallization from oil in water emulsions: particle synthesis and purification of molecular materials, Chem. Eng. Res. Des. 75 (1997) 245-251.

[4] A. Khalil, F. Puel, X. Cosson, O. Gorbatchev, Y. Chevalier, J.-M. Galvan, A. Rivoire, J.-P. Klein, Crystallization-in-emulsion process of a melted organic compound: in situ optical monitoring and simultaneous droplet and particle size measurements, J. Cryst. Growth 342 (2012) 99-109.

[5] A.C.S.M. Carvalho, D. Chicoma, C. Sayer, R. Giudici, Comparison of vinyl acetate - butyl acrylate emulsion copolymerizations conducted in a continuous pulsed sieve plate column reactor and in a batch stirred tank reactor, Macromol. Symp. 243 (2006) 147-158.

[6] X. Ni, Y. Zhang. I. Mustafa, Correlation of polymer particle size with droplet size in suspension polymerisation of methylmethacrylate in a batch oscillatorybaffled reactor, Chem. Eng. Sci. 54 (1999) 841-850.

[7] G.S. Calabrese, S. Pissavini, From batch to continuous flow processing in chemicals manufacturing, AlChE J. 57 (2011) 828-834.

[8] D.A. Paquet, W.H. Ray, Tubular reactors for emulsion polymerization: I, Exp. Invest. AIChE J. 40 (1994) 73-87.

[9] C. Sayer, M. Palma, R. Giudici, Modeling continuous vinyl acetate emulsion polymerization reactions in a pulsed sieve plate column, Ind. Eng. Chem. 41 (2002) 1733-1744.

[10] M. Zerfa, B.W. Brooks, Experimental investigation of vinyl chloride drop behavior during suspension polymerization, J. Appl. Polym. Sci. 65 (1997) 127 134.

[11] F. Jahanzad, S. Sajjadi, B.W. Brooks, On the evolution of particle size average and size distribution in suspension polymerization processes, Macromol. Symp. 206 (2004) 255-262.

[12] F. Jahanzad, S. Sajjadi, B.W. Brooks, Characteristic intervals in suspension polymerisation reactors: an experimental and modelling study, Chem. Eng. Sci. 60 (2005) 5574-5589.

[13] C. Charcosset, I. Limayem, H. Fessi, The membrane emulsification process-a review, J. Chem. Technol. Biotechnol. 79 (2004) 209-218.

[14] K. Urban, G. Wagner, D. Schaffner, D. Röglin, J. Ulrich, Rotor-stator and disc systems for emulsification processes, Chem. Eng. Technol. 29 (2006) 24-31.

[15] E. Lobry, F. Theron, C. Gourdon, N. Le Sauze, C. Xuereb, T. Lasuye, Turbulent liquid-liquid dispersion in SMV static mixer at high dispersed phase concentration, Chem. Eng. Sci. 66 (2011) 5762-5774. 
[16] F. Theron, N. Le Sauze, Comparison between three static mixers for emulsification in turbulent flow, Int. J. Multiphase Flow 37 (2011) 488-500.

[17] F. Theron, N. Le Sauze, A. Ricard, Turbulent liquid-liquid dispersion in Sulzer SMX mixer, Ind. Eng. Chem. Res. 49 (2010) 623-632.

[18] J.T. Davies, Drop sizes of emulsions related to turbulent energy dissipation rates, Chem. Eng. Sci. 40 (1985) 839-842.

[19] S. Schultz, G. Wagner, K. Urban, J. Ulrich, High-pressure homogenization as a process for emulsion formation, Chem. Eng. Technol. 27 (2004) 361-368.

[20] E.W. Barega, E. Zondervan, A.B. de Haan, Influence of physical properties and process conditions on entrainment behavior in a static-mixer settler setup, Ind. Eng. Chem. Res. 52 (2013) 2958-2968.

[21] E. Lobry, C. Gourdon, C. Xuereb, T. Lasuye, Liquid-liquid dispersion in cocurrent disc and doughnut pulsed column effect of the operating conditions, physical properties and materials parameters, Chem. Eng. J. 233 (2013) 24-38.

[22] M. Torab-Mostaedi, A. Ghaemi, M. Asadollahzadeh, P. Pejmanzad, Mass transfer performance in pulsed disc and doughnut extraction columns, Braz. J. Chem. Eng. 28 (2011) 447-456.

[23] C.W. Angle, H.A. Hamza, Predicting the sizes of toluene-diluted heavy oil emulsions in turbulent flow Part 2: Hinze-Kolmogorov based model adapted for increased oil fractions and energy dissipation in a stirred tank, Chem. Eng. Sci. 61 (2006) 7325-7335.

[24] K. Arai, M. Konno, Y. Matanuga, S. Saito, Effect of dispersed-phase viscosity on the maximum stable drop size for breakup in turbulent flow, J. Chem. Eng. Jpn. 10 (1977) 325-330.

[25] R.P. Borwankar, S.I. Chung, D.T. Wasan, Drop sizes in turbulent liquid-liquid dispersions containing polymeric suspension stabilizers. I. The breakage mechanism, J. Appl. Polym. Sci. 32 (1986) 5749-5762.

[26] E.G. Chatzi, C. Kiparssides, Steady-state drop-size distributions in high holup fraction dispersion systems, AIChE J. 41 (1995) 1640-1652.

[27] R.F. Meyer, W.B. Rogers, M.T. McClendon, J.C. Crocker, Producing monodisperse drug-loaded polymer microspheres via cross-flow membrane emulsification: the effects of polymers and surfactants, Langmuir 26 (2010) 14479-14487.

[28] K.K. Singh, S.M. Mahajani, K.T. Shenoy, S.K. Ghosh, Representative drop sizes and drop size distributions in $\mathrm{A} / \mathrm{O}$ dispersions in continuous flow stirred tank, Hydrometallurgy 90 (2008) 121-136.

[29] N.E. Pereira, Characterisation of a Continuous Oscillatory Baffled Tubular Reactor, Heriot-Watt University, Edinburgh, 2002.

[30] N.E. Pereira, X. Ni, Droplet size distribution in a continuous oscillatory baffled reactor, Chem. Eng. Sci. 56 (2001) 735-739.

[31] S. Hall, M. Cooke, A. El-Hamouz, A.J. Kowalski, Droplet break-up by in-line Silverson rotor-stator mixer, Chem. Eng. Sci. 66 (2011) 2068-2079.

[32] H.G. Yuan, G. Kalfas, W.H. Ray, Suspension polymerization, J. Macromol. Sci. C 31 (1991) 215-299.

[33] G.F.M. Hoedemakers, D. Thoenes, Continuous Emulsion Polymerisation in a Pulsed Packed Column, Springer, 1990.

[34] X. Ni, J.C. Johnstone, K.C. Symes, B.D. Grey, D.C. Bennett, Suspension polymerization of acrylamide in an oscillatory baffled reactor: from drops to particles, AIChE J. 47 (2001) 1746-1757.

[35] X. Ni, K.R. Murray, Y. Zhang, D.C. Bennett, T. Howes, Polymer product engineering utilising oscillatory baffled reactors, Powder Technol. 124 (2002) 281-286.

[36] X. Ni, G. Brogan, A. Struthers, D.C. Bennett, S.F. Wilson, A systematic study of the effect of geometrical parameters on mixing time in oscillatory baffled columns, Chem. Eng. Res. Des. 76 (1998) 635-642.

[37] X. Ni, Y.S. De Gélicourt, M.H.I. Baird, N.V.R. Rao, Scale-up of single phase axial dispersion coefficients in batch and continuous oscillatory baffled tubes, Can. J. Chem. Eng. 79 (2001) 444-448.

[38] X. Ni, Y. Zhang, I. Mustafa, An investigation of droplet size and size distribution in methylmethacrylate suspensions in a batch oscillatory-baffled reactor, Chem. Eng. Sci. 53 (1998) 2903-2919.
[39] G.G. Stephens, Suspension Polymerization in Oscillatory Flow, Cambridge University, 1996.

[40] P. Stonestreet, P.M.J. Van Der Veeken, The effects of oscillatory flow and bulk flow components on residence time distribution in baffled tube reactors, Chem. Eng. Res. Des. 77 (1999) 671-684.

[41] Y. Zhang, X. Ni, I. Mustafa, A study of oil-water dispersion in a pulsed baffled reactor, J. Chem. Tech. Biotechnol. 66 (1996) 305-311.

[42] D. Mignard, L.P. Amin, X. Ni, Determination of breakage rates of oil droplets in a continuous oscillatory baffled tube, Chem. Eng. Sci. 61 (2006) 6902-6917.

[43] X. Ni, N.E. Pereira, Parameters affecting fluid dispersion in a continuous oscillatory baffled tube, AIChE J. 46 (2000) 37-45.

[44] V.C. Eze, A.N. Phan, C. Pirez, A.P. Harvey, A.F. Lee, K. Wilson, Heterogeneous catalysis in an oscillatory baffled flow reactor, Catal. Sci. Technol. 3 (2013) 2373-2379.

[45] A.N. Phan, A.P. Harvey, V. Eze, Rapid production of biodiesel in mesoscale oscillatory baffled reactors, Chem. Eng. Technol. 35 (2012) 1214-1220.

[46] F. Castro, A. Ferreira, F. Rocha, A. Vicente, J.A. Teixeira, Continuous-flow precipitation of hydroxyapatite at 37 degrees c in a meso oscillatory flow reactor, Ind. Eng. Chem. Res. 52 (2013) 9816-9821.

[47] L.S. Peixoto, P.A. Melo, M. Nele, J.C. Pinto, Expanded core/shell poly(vinyl acetate)/poly(vinyl alcohol) particles for embolization, Macromol. Mater. Eng. 294 (2009) 463-471.

[48] L.S. Peixoto, F.M. Silva, M.A.L. Niemeyer, G. Espinosa, P.A. Melo, M. Nele, J.C. Pinto, Synthesis of poly(vinyl alcohol) and/or poly(vinyl acetate) particles with spherical morphology and core-shell structure and its use in vascular embolization, Macromol. Symp. 243 (2006) 190-199.

[49] G. Kalfas, H. Yuan, W.H. Ray, Modeling and experimental studies of aqueous suspension polymerization processes.2. Experiments in batch reactors, Ind. Eng. Chem. Res. 32 (1993) 1831-1838.

[50] W.S. Lyoo, H.W. Lee, Synthesis of high-molecular-weight poly(vinyl alcohol) with high yield by novel one-batch suspension polymerization of vinyl acetate and saponification, Colloid Polym. Sci. 280 (2002) 835-840.

[51] W.S. Lyoo, S.G. Lee, J.P. Kim, S.S. Han, C.J. Lee, Low temperature suspension polymerization of vinyl acetate using 2,2'-azobis(2,4-dimethylvaleronitrile) for the preparation of high molecular weight poly(vinyl alcohol) with high yield, Colloid Polym. Sci. 276 (1998) 951-959.

[52] H. Buron, O. Mengual, G. Meunier, I. Cayré, P. Snabre, Optical characterization of concentrated dispersions: applications to laboratory analyses and on-line process monitoring and control, Polym. Int. 53 (2004) 1205-1209.

[53] A. Pizzino, M. Catté, E. Van Hecke, J.-L. Salager, J.-M. Aubry, On-line light backscattering tracking of the transitional phase inversion of emulsions, Colloids Surf. A 338 (2009) 148-154.

[54] A.B. Jahya, G.W. Stevens, H.R.C. Pratt, Pulsed disc-and-doughnut column performance, Solvent Extr. Ion Exch. 27 (2009) 63-82.

[55] K. Sreenivasulu, D. Venkatanarasaiah, Y.B.G. Varma, Drop size distributions in liquid pulsed columns, Bioprocess. Eng. 17 (1997) 189-195.

[56] M. Torab-Mostaedi, A. Ghaemi, M. Asadollahzadeh, Flooding and drop size in a pulsed disc and doughnut extraction column, Chem. Eng. Res. Des. 89 (2011) 2742-2751.

[57] M.L. Van Delden, G.S. Vos, N.J.M. Kuipers, A.B. De Haan, Extraction of caprolactam with toluene in a pulsed disc and doughnut column-part II: experimental evaluation of the hydraulic characteristics, Solvent Extr. Ion Exch. 24 (2006) 519-538.

[58] A.C. Jealous, H.F. Johnson, Power requirements for pulse generation in pulse columns, Ind. Eng. Chem. 47 (1955) 1159-1166.

[59] T. Ueda, K. Takeuchi, M. Kato, Polymer particle formation in suspension polymerization of vinyl chloride and vinyl acetate, J. Polym. Sci. A1 (10) (1972) 2841-2852. 